\title{
FIT OF STATISTICAL FORECASTING MODEL BERDASARKAN VARIABEL ANGKA KEMISKINAN DI PROVINSI KEPULAUAN BANGKA BELITUNG
}

\author{
Desy Yuliana Dalimunthe \\ Program Studi Matematika, Universitas Bangka Belitung \\ desydalimunthe2@gmail.com
}

\begin{abstract}
Poverty is one of the main problems in economic development and is considered to be a variable to measure the success of the economic development of a region. This study is limited to the analysis and determination of the best forecasting statistical model for the variable poverty rate in the Bangka Belitung Islands Province area based on R Square, Root Mean Squared Error (RMSE) and Mean Absolute Percentage Error (MAPE) assessments. This study uses the Exponential Smoothing forecasting method which emphasizes the procedure of continuous improvement of the latest observation objects which hopefully can provide the appropriate results. In general, the double exponential smoothing model from Holt's is the best projection model compared to other exponential smoothing models for projecting poverty data in the Bangka Belitung Islands Province with historical data for 2002-2018 with an increase in projections in 2019 of $0.37 \%$ with Upper Criteria Limit (UCL) of $1.07 \%$ and Lower Criteria Limit (LCL) of $-0.33 \%$ with a value of R Square of 0.627 which means that the independent variable can explain the variance of the dependent variable of $62.7 \%$ of this model, and the value of RMSE is 0.328 and MAPE is 22.162. The results of this model when compared to other models have relatively larger $R$ Squared values and smaller RMSE and MAPE values.
\end{abstract}

Keywords: Poverty, Exponential Smoothing, R Square, Root Mean Squared Error (RMSE), Mean Absolute Percentage Error (MAPE)

\section{PENDAHULUAN}

Kemiskinan merupakan salah satu komponen atau variabel yang dianggap menjadi tolak ukur keberhasilan pembangunan ekonomi suatu wilayah. Pertumbuhan ekonomi diharapkan mampu memberikan dampak positif terhadap peningkatan penyerapan tenaga kerja dan menurunnya tingkat kemiskinan. Pengentasan kemiskinan menjadi salah satu tugas kita bersama agar harapannya pertumbuhan ekonomi baik dari scope negara maupun regional bisa tercapai dengan maksimal. Hal ini tentunya memberikan informasi kepada kita bahwa proyeksi atau peramalan juga memiliki peranan yang penting dalam bidang ekonomi, misalnya perhitungan inflasi, keuntungan perusahaan, pengangguran, dan masih banyak bidang lainnya (Jordi McKenzi, 2011).

Pertumbuhan ekonomi yang tinggi menjadi salah satu prioritas pembangunan di suatu negara dan merupakan salah satu indikator keberhasilan pembangunan. Pertumbuhan ekonomi juga digunakan untuk mengukur kinerja perekonomian suatu negara. Pandangan Mankiw (2006) menyebutkan bahwa pertumbuhan ekonomi yang dihitung dari pertumbuhan Produk Domestik Bruto (PDB) adalah rangkuman aktivitas ekonomi suatu masyarakat selama periode waktu tertentu. Ketika diasumsikan terjadi peningkatan aktivitas ekonomi masyarakat maka akan terjadi peningkatan jumlah nilai barang dan jasa yang dihasilkan dari seluruh kegiatan perekonomian, yang selanjutnya akan meningkatkan jumlah kesempatan kerja dan kemiskinan.

Kemiskinan merupakan salah satu masalah utama dalam pembangunan ekonomi. Pembangunan ekonomi pada hakikatnya bertujuan untuk meningkatkan kesejahteraan masyarakat, meningkatkan pendapatan serta 
pertumbuhan ekonomi di semua sektor pembangunan (Tambunan, 2011).

Gambaran kemiskinan di Provinsi Kepulauan Bangka Belitung dalam kurun waktu 3 tahun yaitu Tahun 2014 sebesar 67,20 ribu jiwa; Tahun 2015 sebesar 74,09 ribu jiwa dan Tahun 2016 sebesar 72,76 ribu jiwa, tentunya hal ini juga menjadi perhatian bagi kita semua agar angka yang tertera tersebut perlahan-lahan dapat diatasi dengan menekan jumlah kemiskinan. Salah satu caranya adalah dengan mengetahui gambaran forecast atau hasil ramalan yang diperoleh dari variabel ini agar segera bisa dilakukan tindakan yang bersifat preventif.

Metode forecasting dari variabel angka kemiskinan Provinsi Kepulauan Bangka Belitung dengan menggunakan metode Exponential Smoothing diharapkan dapat memberikan gambaran mengenai pertumbuhan ekonomi dan sejauh mana kondisi angka kemiskinan di wilayah Provinsi Kepulauan Bangka Belitung. Hal ini semakin diperkuat mengingat pentingnya peramalan (forecasting) yang menjadi dasar bagi perencanaan jangka panjang untuk para pembuat kebijakan. Salah satu pertimbangan yang harus dilakukan dalam memperoleh hasil yang terbaik dalam peramalan adalah pengambilan yang pas mengenai fitur-fitur time series (Evangelos Spiliotis, A 2018).

Adapun metode peramalan yang digunakan dalam penelitian ini adalah metode Exponenetial Smoothing yang menekankan kepada prosedur perbaikan terus-menerus terhadap objek pengamatan terbaru. Metode ini menitik-beratkan pada penurunan prioritas secara eksponensial pada objek pengamatan yang lebih lama. Dengan kata lain, observasi terbaru akan diberikan prioritas lebih tinggi bagi peramalan daripada observasi yang lebih lama atau pengamatan dapat memiliki bobot kepentingan yang berbeda (Ronald R Yager, 2013). Hal ini tentunya lebih menekankan kepada data historical yang fresh sehingga diharapkan hasil peramalan pun memiliki tingkat keakuratan tersendiri.

Berdasarkan ilustrasi diatas, maka perlu dilakukan peramalan (forecasting) terhadap variabel angka kemiskinan di Provinsi Kepulauan Bangka Belitung demi terciptanya hasil prediksi yang cukup mewakili mengenai arah masa depan dari peristiwa-peristiwa ekonomi.

\section{KAJIAN PUSTAKA}

\section{Angka Kemiskinan}

World Bank (dalam Purwanto, 2007) mendefinisikan kemiskinan dengan menggunakan ukuran kemampuan/daya beli, yaitu US \$1 atau US \$2 per kapita per hari. Badan Pusat Statistik mendefinisikan kemiskinan didasarkan pada garis kemiskinan (poverty line). Nilai garis kemiskinan yang digunakan untuk menentukan kemiskinan mengacu pada kebutuhan minimum yang dibutuhkan oleh seseorang yaitu 21,00 kalori per kapita per hari, ditambah dengan kebutuhan minimum non-makan yang merupakan kebutuhan dasar seseorang yang meliputi: papan, sandang, sekolah, transportasi, serta kebutuhan rumah tangga dan individu yang mendasarinya. Pandangan Friedman menyatakan bahwa kemiskinan diartikan sebagai ketidaksamaan kesempatan untuk mengakumulasikan basis kekuasaan sosial. Basis kekuasaan sosial ini meliputi: (1) Modal produktif seperti tanah, alat produksi, perumahan, kesehatan: (2) Sumber keuangan: (3) Organisasi sosial dan politik yang dapat digunakan untuk kepentingan bersama seperti koperasi, partai politik, organisasi sosial: (4) jaringan sosial: (5) Pengetahuan dan keterampilan: 6) Informasi yang berguna untuk kemajuan hidup (Purwanto, 2007).

\section{Konsep Dasar Peramalan}

Peramalan adalah dasar dari segala jenis perencanaan dimana hal ini sangat diperlukan untuk lingkungan yang tidak stabil yaitu menjembatani antara sistem dengan lingkungan (Makridakis dkk, 2000). Peramalan merupakan bagian penting bagi setiap perusahaan/organisasi bisnis dalam setiap pengambilan keputusan manajemen yang sangat signifikan. Peramalan menjadi dasar bagi perencanaan jangka panjang perusahaan. Dalam area fungsional finansial, peramalan memberikan dasar dalam menentukan anggaran dan pengendalian biaya.

\section{Metode Forecast Exponential Smoothing}

Proyeksi (Projection) merupakan kegiatan memprediksi nilai-nilai sebuah variabel berdasarkan nilai yang diketahui dari variabel tersebut atau variabel yang berhubungan. Terdapat dua macam metode yaitu metode kualitatif dan metode kuantitatif. Metode 
kualitatif hanya menggunakan intuisi saja, tanpa menggunakan pendekatan matematis maupun statistik. Situasi, kondisi, dan pengalaman peramal sangat mempengaruhi hasil ramalan. Metode kuantitatif dapat dibedakan menjadi dua cara yaitu metode kausal dan metode time series. Proyeksi yang menggunakan metode Pemulusan Eksponensial (Exponential Smoothing) merupakan salah satu kategori metode time series yang menggunakan pembobotan data masa lalu secara eksponensial.

Metode ini juga bisa dibandingkan dengan beberapa metode peramalan yang lain seperti ARIMA yang juga pernah dilakukan oleh beberapa penelitian terdahulu seperti yang sudah dilakukan oleh Sbrana dan Silvestrini dengan hasil penelitian mereka mengenai menganalisis evaluasi peramalan dengan membandingkan koefisien dari variabelvariabel acak yang termuat didalam ARIMA dan SSOE Exponential Smoothing. Dalam metode eksponential smoothing ini mengandalkan tiga model dasar, diantaranya simple eksponensial smoothing, tren eksponensial smoothing dan musiman eksponensial smoothing (Baki Billah, 2006). Dalam kategori ini terdapat beberapa metode yang umum dipakai, antara lain metode Pemulusan Eksponensial Tunggal (Single Exponential Smoothing) yang digunakan untuk data runtut waktu yang mengikuti pola stasioner dengan bentuk persamaan sebagai berikut:

$$
\hat{Y}_{t+1}=\alpha Y_{t}+(1-\alpha) \hat{Y}_{t}
$$

Dimana:

$\hat{Y}_{t+1}=$ nilai ramalan untuk periode berikutnya

$\alpha=$ konstanta pemulusan

$Y_{\mathrm{t}} \quad=$ data baru atau nilai $Y$ yang sebenarnya pada periode $\mathrm{t}$

$\hat{Y}_{t} \quad=$ nilai pemulusan yang lama atau ratarata pemulusan hingga periode $\mathrm{t}-1$

Metode Pemulusan Eksponensial Ganda Satu Parameter dari Brown (Brown's OneParameter Double Exponential Smoothing) Bentuk umum yang digunakan untuk menghitung ramalan adalah:
1. $A_{t}=\alpha Y_{t}+(1-\alpha) A_{t-1}$
2. $A_{t}^{\prime}=\alpha A_{t}+(1-\alpha) A_{t-1}^{\prime}$
3. $a_{t}=2 A_{t}-A_{t}^{\prime}$

4. $b_{t}=\frac{\alpha}{1-\alpha}\left(A_{t}-A_{t}^{\prime}\right)$

dengan persamaan forecast pada periode ke $p$ sebagai berikut:

$$
\hat{Y}_{t+p}=a_{t}+b_{t} p
$$

Dimana :

$A_{t} \quad=$ nilai pemulusan eksponensial

$A^{\prime} t=$ nilai pemulusan eksponensial ganda

$\alpha \quad=$ konstanta pemulusan

$a_{t}=$ perbedaan antara nilai-nilai pemulusan eksponensial

$b_{t}=$ faktor penyesuai tambahan = pengukuran slope suatu kurva

$Y_{t} \quad=$ nilai aktual pada periode $\mathrm{t}$

$p \quad=$ jumlah periode ke depan yang akan diramalkan

Metode selanjutnya adalah metode Pemulusan Ganda Dua Parameter (Holt's TwoParameter Double Exponential Smoothing) yang digunakan dalam peramalan data runtut waktu yang mengikuti suatu tren linier. Bentuk umum yang digunakan untuk menghitung ramalan adalah:

1. $A_{t}=\alpha Y_{t}+(1-\alpha)\left(A_{t-1}+T_{t-1}\right)$

2. $T_{t}=\beta\left(A_{t}-A_{t-1}\right)+(1-\beta) T_{t-1}$

Persamaan yang digunakan untuk membuat peramalan pada periode $\mathrm{p}$ yang akan datang adalah:

$$
\hat{Y}_{t+p}=A_{t}+T_{t} p
$$

Dimana :

$\mathrm{A}_{\mathrm{t}} \quad=$ nilai pemulusan eksponensial

$\alpha=$ konstanta pemulusan untuk data

$(0 \leq \alpha \leq 1)$

$\beta \quad=$ konstanta pemulusan untuk estimasi

$\operatorname{tren}(0 \leq \beta \leq 1)$

$Y t=$ nilai aktual pada periode $t$

Tt = estimasi tren

$p \quad=$ jumlah periode ke depan yang akan diramalkan

Agar dapat memulai sistem peramalan metode Brown kita memerlukan $\mathrm{A}_{1}$, karena $A_{2}=\alpha Y_{2}+(1-\alpha)\left(A_{1}+T_{1}\right)$, karena pada saat $\mathrm{t}$ $=1$, nilai $\mathrm{A}_{1}$ tidak diketahui, maka kita dapat menggunakan nilai observasi pertama $\left(\mathrm{Y}_{1}\right)$. Untuk estimasi tren pada saat $\mathrm{t}=1$, nilai $\mathrm{T}_{1}$ tidak diketahui, maka kita dapat menggunakan selisih nilai observasi kedua $\left(\mathrm{Y}_{2}\right)$ dengan nilai observasi pertama $\left(Y_{1}\right)$, yaitu $T_{1}=Y_{2}-Y_{1}$. 
Metode terakhir dari pemulusan eksponensial ini yakni Pemulusan Eksponensial Tripel dari Winter (Winter's Three-Parameter Triple Exponential Smoothing) Digunakan dalam peramalan data runtut waktu yang mengikuti suatu pola musiman. Didasarkan pada 3 persamaan pemulusan, yaitu: untuk unsur stasioner, untuk tren, dan untuk musiman. Bentuk umum yang digunakan untuk menghitung ramalan adalah:

Pemulusan eksponensial

$$
A_{t}=\alpha \frac{Y_{t}}{S_{t-L}}+(1-\alpha)\left(A_{t-1}+T_{t-1}\right)
$$

Estimasi tren

$$
T_{t}=\beta\left(A_{t}-A_{t-1}\right)+(1-\beta) T_{t-1}
$$

Estimasi musiman

$$
S_{t}=\mu \frac{Y_{t}}{A_{t}}+(1-\mu) S_{t-L}
$$

Persamaan yang digunakan untuk membuat peramalan pada periode $p$ yang akan datang adalah:

$$
\hat{Y}_{t+p}=\left(A_{t}+T_{t} p\right) S_{t-L+p}
$$

Dimana :

$$
\begin{array}{ll}
A_{t} & =\text { nilai pemulusan eksponensial } \\
\alpha & =\text { konstanta pemulusan untuk data }(0 \leq \\
& \alpha \leq 1) \\
\beta & \quad=\text { konstanta pemulusan untuk estimasi } \\
& \text { tren }(0 \leq \beta \leq 1) \\
\mu & =\text { konstanta pemulusan untuk estimasi } \\
& \text { musiman }(0 \leq \mu \leq 1) \\
Y_{t} & =\text { nilai aktual pada periode } \mathrm{t} \\
T_{t} & =\text { estimasi tren } \\
S_{t} & =\text { estimasi musiman } \\
L & =\text { panjangnya musim } \\
p & =\text { jumlah periode ke depan yang akan } \\
& \text { diramalkan. }
\end{array}
$$

Exponential smoothing merupakan salah satu metode untuk memperoleh proyeksi data $n$ tahun kedepan dari data time series dimana prosedur perbaikan terus-menerus terhadap objek pengamatan terbaru.

Ketika terdapat tren dalam data, kita bisa menggunakan metode penghalusan eksponensial Holt dengan dua parameter (atau sering disebut dengan penghalusan eksponensial ganda) yang menggunakan parameter $\alpha$ sebagai parameter dalam penghalusan "level" atau rata-rata dari data, sedangkan parameter kedua, yakni $\beta$ sebagai parameter untuk penghalusan tren. Metode Holt
Winters ini digunakan ketika data menunjukkan adanya tren dan perilaku musiman (Makridakis, 1999).

Terkait data time series yang mengandung musiman, telah dikembangkan parameter persamaan ketiga yang disebut metode "HoltWinters" sesuai dengan nama penemunya. Terdapat dua model Holt-Winters yang tergantung pada tipe musimannya yaitu Multiplicatif Seasonal Model dan Additif Seasonal Model. Metode lainnya yaitu single exponential smoothing yang menitik beratkan pada data yang hanya bersifat stasioner dan double exponential smoothing yang dapat menitik beratkan pada tren dan dapat digunakan untuk hampir segala jenis data stasioner atau non stasioner sepanjang data tersebut namun tidak mengandung faktor musiman. Tetapi jika terdapat musiman, metode triple exponential smoothing ini dijadikan cara untuk meramalkan data yang mengandung faktor musiman.

Metode triple exponential smoothing didasarkan atas tiga persamaan pemulusan masing-masing untuk unsur stasioner, tren dan musiman. Metode penghalusan ekponensial ini bisa dikombinasikan atau dibandingkan dengan beberapa metode lainnya misalnya metode klastering dengan tetap menggunakan kriteria pemilihan metode terbaik seperti Rank sMAPE, Mean sMAPE, Rank MASE, dan Mean MASE (Dantas, 2018). Pemilihan metode yang terbaik dalam penelitian ini menggunakan kriteria berdasarkan R Square, Root Mean Squared Error (RMSE) and Mean Absolute Percentage Error (MAPE). MAPE merupakan salah satu pengukuran yang paling sering digunakan dalam mengukur tingkat keakuratan proyeksi (Kim, 2018).

\section{METODE PENELITIAN}

Metode forecasting yang digunakan dalam penelitian ini adalah metode Pemulusan Ekponensial (Exponential Smoothing). Dalam tahap awal dilakukan identifikasi model runtun waktu yang mungkin digunakan untuk memodelkan sifat-sifat data. Identifikasi secara sederhana dilakukan secara visual dengan melihat plot dari data, untuk melihat adanya komponen tren, musiman, non stasioneritas dalam variansi dan lain-lain.

Selanjutnya akan ditentukan model yang fit dari ketiga jenis model yang ada di dalam metode pemulusan eksponensial ini, yakni Simple Exponential Smoothing, Holt Winters 
Exponential Smoothing dan Triple Exponential Smoothing. Langkah terakhir dalam proses analisis dan pemilihan model peramalan yang terbaik ini adalah dengan menentukan model terbaik atau model yang fit dari ketiga jenis model yang ada dengan membandingkan nilai R Square, Root Mean Square Error (RMSE), dan Mean Absolute Percentage Error (MAPE). Untuk nilai $\mathrm{R}$ square akan dipilih nilai yang terbesar yang artinya seberapa jauh kemampuan variabel bebas bisa menjelaskan varians dari variabel terikat berdasarkan model yang dipilih, sedangkan nilai RMSE dan MAPE akan dipilih nilai yang terkecil dari ketiga model yang ada.

\section{HASIL DAN PEMBAHASAN}

Dalam penelitian ini juga menggunakan data runtun waktu yakni berupa data angka kemiskinan Provinsi Kepulauan Bangka Belitung yang dimulai pada Tahun 2002-2018 (ribu jiwa) yang disajikan seperti Tabel 5.1 berikut ini:

Tabel 1. Jumlah Penduduk Miskin Provinsi Kepulauan Bangka Belitung

\begin{tabular}{|c|c|}
\hline Tahun & $\begin{array}{c}\text { Jumlah Penduduk Miskin } \\
\text { (Ribu Jiwa) }\end{array}$ \\
\hline 2002 & 106,2 \\
\hline 2003 & 98,2 \\
\hline 2004 & 91,8 \\
\hline 2005 & 95,3 \\
\hline 2006 & 117,41 \\
\hline 2007 & 95,1 \\
\hline 2008 & 80,28 \\
\hline 2009 & 76,01 \\
\hline 2010 & 67,75 \\
\hline 2011 & 65,55 \\
\hline 2012 & 70,2 \\
\hline 2013 & 69,4 \\
\hline 2014 & 67,2 \\
\hline 2015 & 74,09 \\
\hline 2016 & 72,76 \\
\hline 2017 & 74,09 \\
\hline 2018 & 76,26 \\
\hline
\end{tabular}

Sumber: Badan Pusat Statistik (BPS) Provinsi

Kepulauan Bangka Belitung, 2019
Proses penentuan model terbaik ini akan membandingkan nilai $\mathrm{R}$ square, RMSE dan MAPE dari masing-masing model. Untuk nilai $\mathrm{R}$ square akan dipilih nilai yang terbesar yang artinya seberapa jauh kemampuan variabel bebas bisa menjelaskan varians dari variabel terikat berdasarkan model yang dipilih, sedangkan nilai RMSE dan MAPE akan dipilih nilai yang terkecil dari ketiga model yang ada. Berikut hasil yang diperoleh untuk model simple exponential smoothing:

Tabel 2. Hasil Metode Simple Exponential Smoothing

\begin{tabular}{|c|c|c|c|c|}
\hline Fit Statistic & Mean & SE & Minimum & Maximum \\
\hline Stationary R-squared & 123 & & 123 & ,123 \\
\hline R-squared &, 553 & &, 553 &, 553 \\
\hline RMSE & 348 & & 348 & ,348 \\
\hline MAPE & 23,073 & & 23,073 & 23,073 \\
\hline MaxAPE & 80,599 & & 80,599 & 80,599 \\
\hline MAE &, 244 & &, 244 &, 244 \\
\hline MaxAE & ,863 & & ,863 & ,863 \\
\hline Normalized BIC & $-1,944$ & & $-1,944$ & $-1,944$ \\
\hline
\end{tabular}

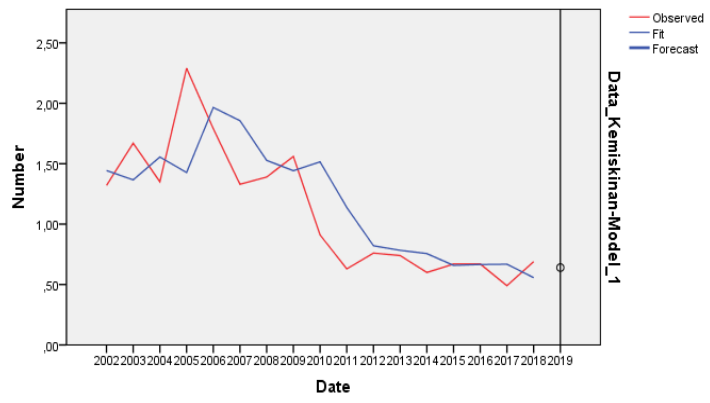

Gambar 1. Grafik Simple Exponential Smoothing

Berdasarkan Gambar 1 di atas, terlihat bahwa berdasarkan model ini diperoleh nilai $\mathrm{R}$ Square sebesar 0,553 yang artinya variabel bebas dapat menjelaskan varians dari variabel terikat sebesar 55,3\% dari model ini, dan nilai dari RMSE sebesar 0,348 dan MAPE sebesar 23,073. Hasil ini tentunya akan dibandingkan dengan model yang lainnya dari metode pemulusan eksponensial, yakni model ganda satu parameter dari Brown's dengan hasil sebagai berikut: 
Tabel 3. Hasil Metode Pemulusan Ekponensial Brown's

\begin{tabular}{|c|c|c|c|c|c|}
\hline \multirow[b]{2}{*}{ Fit Statistic } & \multirow[b]{2}{*}{ Mean } & \multirow[b]{2}{*}{ SE } & \multirow[b]{2}{*}{ Minimum } & \multicolumn{2}{|r|}{ Model Fit } \\
\hline & & & & Maximum & 5 \\
\hline Stationary R-squared &, 655 & &, 655 & .655 & ,655 \\
\hline R-squared &, 524 & & .524 & 524 & ,524 \\
\hline RMSE & 359 & & 359 & 359 &, 359 \\
\hline MAPE & 23,963 & & 23,963 & 23,963 & 23,963 \\
\hline MaxAPE & 78,488 & & 78,488 & 78,488 & 78,488 \\
\hline MAE &, 256 & &, 256 &, 256 &, 256 \\
\hline MaxAE &, 887 & &, 887 &, 887 & ,887 \\
\hline Normalized BIC & $-1,880$ & & $-1,880$ & $-1,880$ & $-1,880$ \\
\hline
\end{tabular}

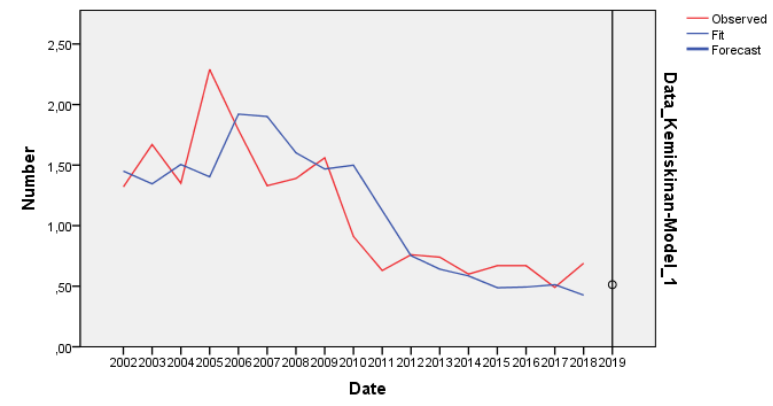

Gambar 2. Grafik Ekponensial Brown's

Berdasarkan Gambar 2 di atas, terlihat bahwa berdasarkan model ini diperoleh nilai $\mathrm{R}$ Square sebesar 0,524 yang artinya variabel bebas dapat menjelaskan varians dari variabel terikat sebesar 52,4\% dari model ini, dan nilai dari RMSE sebesar 0,359 dan MAPE sebesar 23,963. Hasil dari model ini jika dibandingkan dengan nilai sebelumnya memiliki nilai $R$ Square yang lebih kecil dan nilai RMSE serta MAPE yang jauh lebih besar dibandingkan dengan simple exponential smoothing yang secara langsung memberikan informasi bahwa model ini bukan model terbaik dari kedua jenis model yang sudah dianalisis.

Selanjutnya, hasil kedua model yang sudah ada ini akan dibandingkan dengan model yang lainnya dari metode pemulusan eksponensial, yakni model ganda satu parameter Holt's dengan hasil sebagai berikut:

Tabel 4. Hasil Metode Pemulusan Ekponensial Holt's

\begin{tabular}{|c|c|c|c|c|}
\hline Fit Statistic & Mean & SE & Minimum & Maximum \\
\hline Stationary R-squared & .760 & &, 760 &, 760 \\
\hline R-squared &, 627 & & .627 &, 627 \\
\hline RMSE & 328 & & ,328 &, 328 \\
\hline MAPE & 22,162 & & 22,162 & 22,162 \\
\hline MaxAPE & 74,414 & & 74,414 & 74,414 \\
\hline MAE &, 234 & &, 234 &, 234 \\
\hline MaxAE & ,787 & & ,787 & ,787 \\
\hline Normalized BIC & $-1,894$ & & $-1,894$ & $-1,894$ \\
\hline
\end{tabular}

Forecast

\begin{tabular}{|ll|r|}
\hline Model & & \multicolumn{1}{|c|}{2019} \\
\hline Data_Kemiskinan- & Forecast &, 37 \\
Model_1 & UCL & 1,07 \\
& LCL &,- 33 \\
\hline
\end{tabular}

For each model, forecasts start after the last nonmissing in the range of the requested estimation period, and end at the last period for which nonmissing values of all the predictors are available or at the end date of the requested forecast period, whichever is earlier.

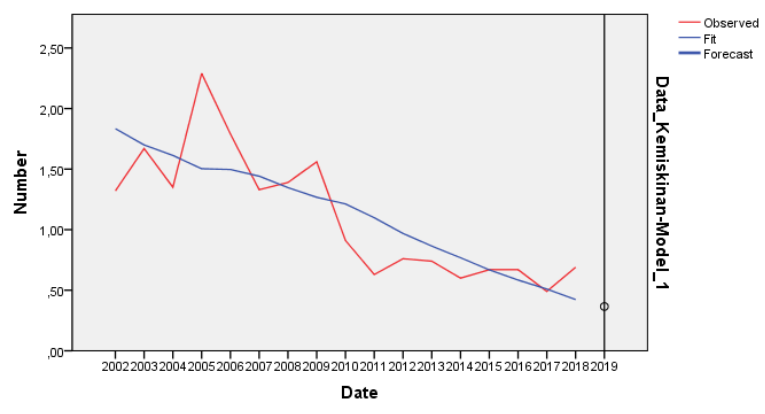

Gambar 3. Grafik Ekponensial Holt's

Berdasarkan Gambar 3 di atas, hasil yang diberikan dari model ketiga dari Holt's ini diperoleh nilai $\mathrm{R}$ Square sebesar 0,627 yang artinya variabel bebas dapat menjelaskan varians dari variabel terikat sebesar $62,7 \%$ dari model ini, dan nilai dari RMSE sebesar 0,328 dan MAPE sebesar 22,162. Hasil dari model ini jika dibandingkan dengan nilai model sebelumnya memiliki nilai $\mathrm{R}$ Square yang relatif lebih besar dan nilai RMSE serta MAPE yang lebih kecil dibandingkan dengan kedua model sebelumnya atau dengan kata lain sejauh ini model pemulusan ekponensial ganda dari Holt's ini merupakan model terbaik. Namun, model dari Holt's ini masih akan dibandingkan dengan model pemulusan eksponensial terakhir yakni Triple Exponential Smoothing dengan hasil sebagai berikut:

Tabel 5. Hasil Metode Triple Exponential Smoothing

\begin{tabular}{|c|c|c|c|c|}
\hline Fit Statistic & Mean & SE & Minimum & Maximum \\
\hline Stationary R-squared &, 389 & &, 389 &, 389 \\
\hline R-squared &, 627 & &, 627 &, 627 \\
\hline RMSE & 340 & &, 340 &, 340 \\
\hline MAPE & 22,560 & & 22,560 & 22,560 \\
\hline MaxAPE & 75,137 & & 75,137 & 75,137 \\
\hline MAE &, 237 & &, 237 &, 237 \\
\hline MaxAE &, 771 & &, 771 &, 771 \\
\hline Normalized BIC & $-1,659$ & & $-1,659$ & $-1,659$ \\
\hline
\end{tabular}




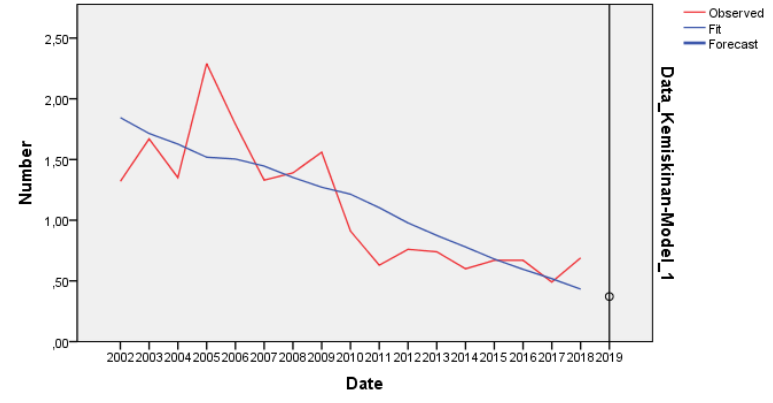

Gambar 4. Grafik Triple Exponential Smoothing

Informasi yang diberikan berdasarkan model Triple Exponential Smoothing ini diperoleh nilai $\mathrm{R}$ Square sebesar 0,627 yang artinya variabel bebas dapat menjelaskan varians dari variabel terikat sebesar $62,7 \%$ dari model ini, dan nilai dari RMSE sebesar 0,340 dan MAPE sebesar 22,560. Hasil yang diberikan dari model ini jika dibandingkan dengan nilai model-model sebelumnya bahwa model ini bukan model terbaik dari keseluruhan jenis model pemulusan eksponensial yang sudah dianalisis atau secara ringkas perbandingan nilai hasil proyeksi untuk kriteria pemilihan model terbaik ini terangkum pada Tabel 6 berikut:

Tabel 6. Hasil Pemilihan Model Statistik Proyeksi Terbaik

\begin{tabular}{|l|c|c|c|c|}
\hline Kriteria & $\begin{array}{l}\text { Simple } \\
\text { Exp } \\
\text { Smoot } \\
\text { hing }\end{array}$ & $\begin{array}{l}\text { Double } \\
\text { Exp } \\
\text { Smoothing } \\
\text { Holt's }\end{array}$ & $\begin{array}{l}\text { Double } \\
\text { Exp } \\
\text { Smooth } \\
\text { ing } \\
\text { Brown }\end{array}$ & $\begin{array}{l}\text { Triple Exp } \\
\text { Smoothing }\end{array}$ \\
\hline $\begin{array}{l}\text { R } \\
\text { Square }\end{array}$ & 0,553 & 0,627 & 0,524 & 0,627 \\
\hline RMSE & 0,348 & 0,328 & 0,359 & 0,340 \\
\hline MAPE & $\begin{array}{c}23,07 \\
3\end{array}$ & 22,162 & 23,693 & 22,560 \\
\hline $\begin{array}{l}\text { Proyek } \\
\text { si }\end{array}$ & 0,64 & 0,37 & 0,51 & 0,37 \\
\hline
\end{tabular}

Sumber: Data Diolah (2019)

Secara umum model pemulusan eksponensial ganda dari Holt's merupakan model proyeksi terbaik untuk melakukan proyeksi data kemiskinan yang ada di Provinsi Kepulauan Bangka Belitung dengan data historical Tahun 2002-2018 dengan hasil peningkatan proyeksi pada tahun 2019 sebesar 0,37\% dengan Upper Criteria Limit (UCL) atau batas atas hasil proyeksi peningkatannya sebesar 1,07\% dan Lower Criteria Limit (LCL) atau batas bawah hasil proyeksi penurunannya sebesar $-0,33 \%$.

Hasil analisis yang diperoleh ini harapannya dapat membantu para stakeholders yang berkepentingan untuk melakukan tindakan preventif. Proses pengolahan data yang pertama ini akan dilihat bagaimana model tren yang terjadi dari angka kemiskinan yang terjadi, selanjutnya melakukan analisis forecasting dengan model pemulusan eksponensial untuk diambil model yang fit dari hasil yang ada.

\section{KESIMPULAN DAN SARAN}

\section{Kesimpulan}

Berdasarkan hasil dan pembahasan yang sudah dibahas sebelumnya, maka dapat diambil beberapa kesimpulan diantaranya:

1. Data angka kemiskinan Provinsi Kepulauan Bangka Belitung Tahun 2002-2018 mengandung suatu pola tren dalam data sesuai dengan hasil pemilihan model proyeksi terbaik dari metode pemulusan eksponensial. Adapun pola tren dalam data yang dimaksud secara umum lebih mengarah kepada pola tren turun (downward tren) untuk variabel angka kemiskinan yang ada di Provinsi Kepulauan Bangka Belitung Tahun 2002-2018.

2. Berdasarkan kriteria pemilihan model proyeksi yang terbaik, maka model dari Holt's Exponensial Smoothing merupakan model proyeksi yang terbaik dengan nilai $\mathrm{R}$ Square sebesar 0,627 yang artinya variabel bebas dapat menjelaskan varians dari variabel terikat sebesar $62,7 \%$ dari model ini, dan nilai dari RMSE sebesar 0,328 dan MAPE sebesar 22,162. Hasil dari model ini jika dibandingkan dengan model lainnya memiliki nilai $\mathrm{R}$ Squared yang relatif lebih besar dan nilai RMSE serta MAPE yang lebih kecil.

3. Hasil peningkatan proyeksi pada tahun 2019 sebesar 0,37\% dengan Upper Criteria Limit (UCL) atau batas atas hasil proyeksi peningkatannya sebesar 1,07\% dan Lower Criteria Limit (LCL) atau batas bawah hasil proyeksi penurunannya sebesar $-0,33 \%$.

\section{Saran}

Beberapa hal yang disarankan dalam format laporan akhir selanjutnya demi adanya pengembangan lebih lanjut diantaranya:

1. Masih banyak kekurangan dari pemilihan model proyeksi yang ada mengingat terbatasnya data histories yang tersedia, walaupun model pemulusan eksponensial menitik-beratkan pada penurunan prioritas 
secara eksponensial pada objek pengamatan yang lebih lama.

2. Dalam melakukan pemilihan model proyeksi yang terbaik, masih banyak kriteria lain yang bisa dijadikan pertimbangan dalam membuat keputusan, tidak hanya berdasarkan kriteria nilai $\mathrm{R}$ Squared, RMSE dan MAPE saja.

3. Bisa dilakukan komparasi dengan beberapa model proyeksi lainnya untuk mendapatkan hasil yang maksimal terkait hasil proyeksi.

4. Variabel yang diteliti tidak saja berkaitan dengan variabel ekonomi saja, melainkan bisa variabel lain yang bersifat time series tentunya.

5. Pemilihan model terbaik juga bisa dilakukan untuk beberapa model proyeksi data time series lainnya.

\section{UCAPAN TERIMA KASIH}

Penulis mengucapkan terima kasih kepada semua pihak yang sudah terlibat dalam penyusunan jurnal hasil penelitian ini, terutama kepada Universitas Bangka Belitung yang sudah mendanai penelitian ini sehingga harapannya hasil penelitian ini bisa memberikan manfaat kepada semua pihak/stakeholders.

\section{DAFTAR PUSTAKA}

Baki Billah, Maxwell. 2006. Exponential Smoothing Model Selection for Forecasting. Interntional journal of forecasting 22, 239-247

Dornbusch, Rudiger, dkk. 2008. Makroekonomi. Jakarta: PT. Media Global Edukasi.

Evangelos Spiliotis, A. 2018. Are Forecasting Competitions Data Representatitive of The Reality? Interntional journal of forecasting

Kuncoro, Mudrajad. 2003. Metode Riset untuk Bisnis dan Ekonomi. Jakarta: Erlangga

Makridakis S, Steven C, Wheelwright, Victor E and Mc Gee. 2000. Metode dan Aplikasi Peramalan, Jilid I, Edisi Kedua. Jakarta: Binarupa Aksara.

Mankiw, N. Gregory. 2006. Makroekonomi. Jakarta: Erlangga.
McKenzi, Jordi. 2011. Mean Absolute Percentage Error and Bias in Econometric Forecasting. Economic Letters 113, 259262

Purwanto, E.A. Mengkaji Potensi Usaha Kecil dan Menengah (UKM) untuk Pembuatan Kebijakan Anti Kemiskinan di Indonesia. Jurnal Ilmu Sosial dan Ilmu Politik, Volume 10, Nomor 3, Maret2, hal. 295-330

R Yager, Ronald. 2013. Exponential Smoothing with Credibility Weighted Observations. Information Sciences 252, 96-105

Rosadi, D. 2011. Analisis Ekonometrika dan Runtun Waktu Terapan dengan Eviews, ANDI, Yogyakarta.

Sabrana G, Silvestrini. 2014. Random Switching Exponential Smoothing: A New Estimation Approach. International journal of Production Economics.

Sugiyono. 2008. Metode Penelitian Bisnis. Bandung: Alfabeta

Kim, S. 2018. A new metric of absolute percentage error for intermittent. International Journal of Forecasting, 669679.

Tambunan. 2011. Perekonomian Indonesia: Teori dan Temuan Empiris. Jakarta: Ghalia Indonesia.

Dantas, T. M. 2018. Improving time series forecasting: An approach combining bootstrap aggregation, clusters and exponential smoothing. International Journal of Forecasting, 748-761. 